\title{
Olfactory Neuroblastoma (Esthesioneuroblastoma) following Retro-Orbital Irradiation for Graves' Ophthalmopathy
}

\section{Tamjid $\mathrm{B}^{*}$, Cher $\mathrm{L}^{1}$, Wada $\mathrm{M}^{2}$, Kalnins $\mathrm{R}^{3}$ and Gan $\mathrm{H}^{1}$}

${ }^{1}$ Medical Oncology Department, Austin Health, Melbourne, Australia

${ }^{2}$ Radiation Oncology Department, Austin Health, Melbourne, Australia

${ }^{3}$ Anatomical Pathology Department, Austin Health, Melbourne, Australia

*Corresponding author: Tamjid B, M.D., Medical Oncology Department, Austin Hospital, 145 Studley Rd, Heidelberg VIC 3084, Tel: +613 9496 5000, E-mail: babaktamjid@hotmail.com

Citation: Tamjid B, Cher L, Wada M, Kalnins R, Gan H (2014) Olfactory Neuroblastoma (Esthesioneuroblastoma) following Retro-Orbital Irradiation for Graves' Ophthalmopathy. J Case Rep Stud 2(1): 103. doi: 10.15744/2348-9820.1.403

Received Date: January 16, 2014 Accepted Date: February 21, 2014 Published Date: February 24, 2014

\begin{abstract}
Background: Olfactory neuroblastoma is a rare malignancy of the nasal cavity.

Methods: We describe a case of radiation-induced olfactory neuroblastoma in a patient with a history of radiation for Graves' ophthalmopathy. We also reviewed the literature and found four other cases of radiation-induced olfactory neuroblastoma reported since 2000, suggesting prior radiotherapy as one risk factor for this disease.

Results: We treated the patient with multimodality treatment consisting of surgery, radiotherapy and chemotherapy (6 cycles of cisplatin/etoposide). Despite the previously irradiation, treatment was well tolerated without excessive short or long term radiation toxicity. The patient remains in long term remission with no evidence of loco-regional recurrence or systemic metastasis after 12 years of follow-up.

Conclusions: Prior radiotherapy appears to be a risk factor in a handful of cases of this rare malignancy. Although the literature is limited for radiation-related olfactory neuroblastoma, outcomes appear generally poorer for this group but highly variable. With careful patient selection, aggressive multi-modality therapy including post-operative radiotherapy may be feasible.
\end{abstract}

Keywords: Olfactory neuroblastoma; Radiation-induced; Multimodality treatment; Chemotherapy; Radiotherapy

\section{Introduction}

Malignancies of the nasal cavity are uncommon and comprise less than $1 \%$ of all malignancies [1]. While almost half of the sinonasal cancers are squamous cell carcinomas [2], olfactory neuroblastoma, also known as esthesioneuroblastoma, comprise less than 6\% of nasal malignancies [3-6]. After the initial description in 1924 by Berger and Luc, less than 1,000 cases were reported until 1997 [7]. These are tumours of neuroectodermal origin which are thought to arise from the olfactory epithelium in the nasal cavity [8]. The mean age at presentation is 53 years, with most cases occurring in patients between 40 and 70 years of age. Although there is a male predominance [9], no other risk factor is commonly associated with this disease. The most widely used staging system is the Kadish clinical staging system based upon the extent of the primary tumour [10]. Kadish stage A tumours are confined to the nasal cavity, stage B tumours have involvement of one or more paranasal sinuses, and stage $\mathrm{C}$ tumours extend beyond the nasal cavity and paranasal sinuses. This was subsequently modified to include another group of patients with lymph node or distant metastases as stage D tumours [11]. A retrospective analysis of 261 patients with modified Kadish staging showed 10 year disease-specific survival rates of $90 \%, 68 \%, 67 \%$ and $36 \%$ for patients with stage A, B, C, and D respectively [9]. Furthermore, tumour grade may also be a prognostic factor with Morita et al. [11] showing that five-year survival rate was $80 \%$ for the low-grade tumours and $40 \%$ for the high-grade tumours $(\mathrm{P}=0.0001)$.

The treatment of olfactory neuroblastoma routinely incorporates surgery and post-operative radiotherapy to 55-65 Gy [12-17]. Multiple studies have incorporated various chemotherapy regimens in an effort to improve outcomes [18-20], although there is no randomised data to definitively show that this improves outcomes. Nevertheless, some promising results have been shown in studies of patients with advanced or high grade tumours by Eich et al. [19]. They described a study of 47 patients with more advanced local disease (Kadish stage B and C) who were treated with surgery alone (seven patients), surgery with post-operative radiotherapy (15 patients), definitive radiotherapy with or without chemotherapy (12 patients) and trimodality therapy (with 13 patients received surgery plus chemotherapy plus postoperative radiotherapy). The 5 year overall survival (OS) for the whole group 
was $64 \%$ and the 5-year event-free survival (EFS) was 50\%. Patients with trimodality treatment appeared to have better 5-year EFS compared to other patients $(74 \%$ vs $41 \%$; $\mathrm{p}=0.05)$. The 11 patients with Kadish stage $\mathrm{C}$ tumours appeared to derive the most benefit with trimodality therapy (5-year EFS of $72 \%$ vs $17 \%$; $=0.01$ ). This group of patients also tended to have an improved OS ( $69 \%$ vs $47 ; \mathrm{p}=0.19)$ compared with the other treatment groups. Interestingly, none of the patients with multimodality treatment had a metastatic relapse [19].

Here we report on a case of radiotherapy-related olfactory neuroblastoma who was safely re-treated with sequential (dose-reduced) radiotherapy and chemotherapy with an excellent outcome.

\section{Case Report}

A 48 year old male presented with a two month history of occasional headaches, left nostril epistaxis, blocked nose and loss of sense of smell in December 2000. His past medical history included hyperthyroidism and Graves' ophthalmopathy, for which he was treated with anti-thyroid medications and $20 \mathrm{~Gy}$ of radiotherapy to his retro-orbital area in 1992. MRI at the time of presentation (Figure 1) revealed a heterogeneous mass lesion in the left nasal cavity with involvement of the medial wall of the left orbit, multiple paranasal sinuses (left ethmoid, bilateral maxillary sinuses and left sphenoid sinuses) and bilateral frontal lobe invasion. The patient underwent an endoscopic biopsy which reported the presence of olfactory neuroblastoma. He underwent left lateral rhinotomy, medial ethmoidectomy, maxillectomy, sphenoidectomy, and a frontal craniotomy with macroscopic clearance of intracranial disease. Histology confirmed the diagnosis of olfactory neuroblastoma and the tumour was considered high grade (Figure 2). A positive surgical margin was noted in the region of the medial aspect of pterygopalatine fossa although post-operative MRI showed no evidence of macroscopic residual disease. The patient's final stage was Kadish C [10].

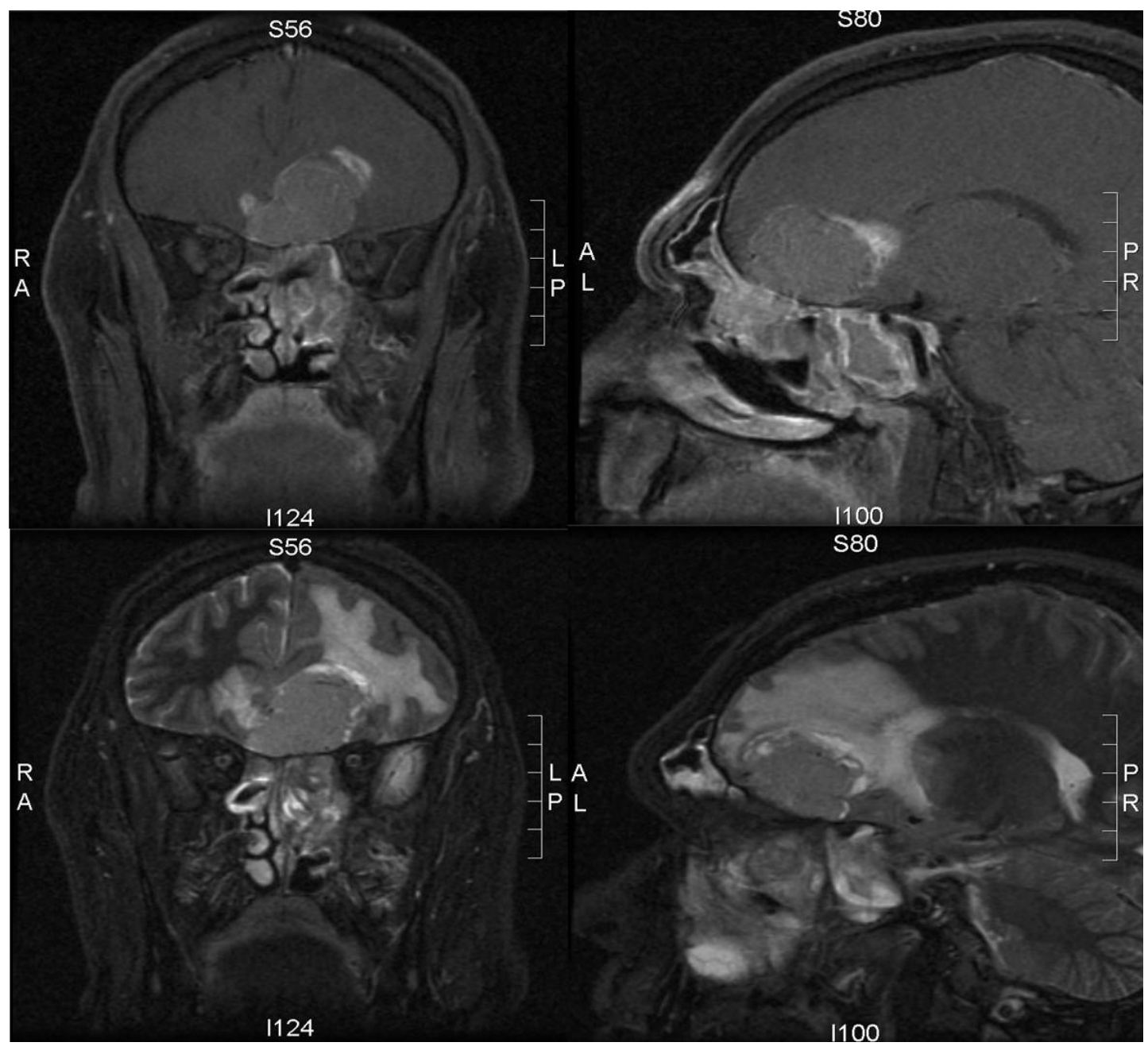

Figure 1: Post gadolinium T1 sagittal and coronal images illustrating the olfactory neuroblastoma in the left nasal cavity invading the surrounding structures with intracranial extension (A, B) with STIR (Short TI Inversion Recovery) imaging showing the extent of intracerebral oedema $(\mathrm{C}, \mathrm{D})$. 


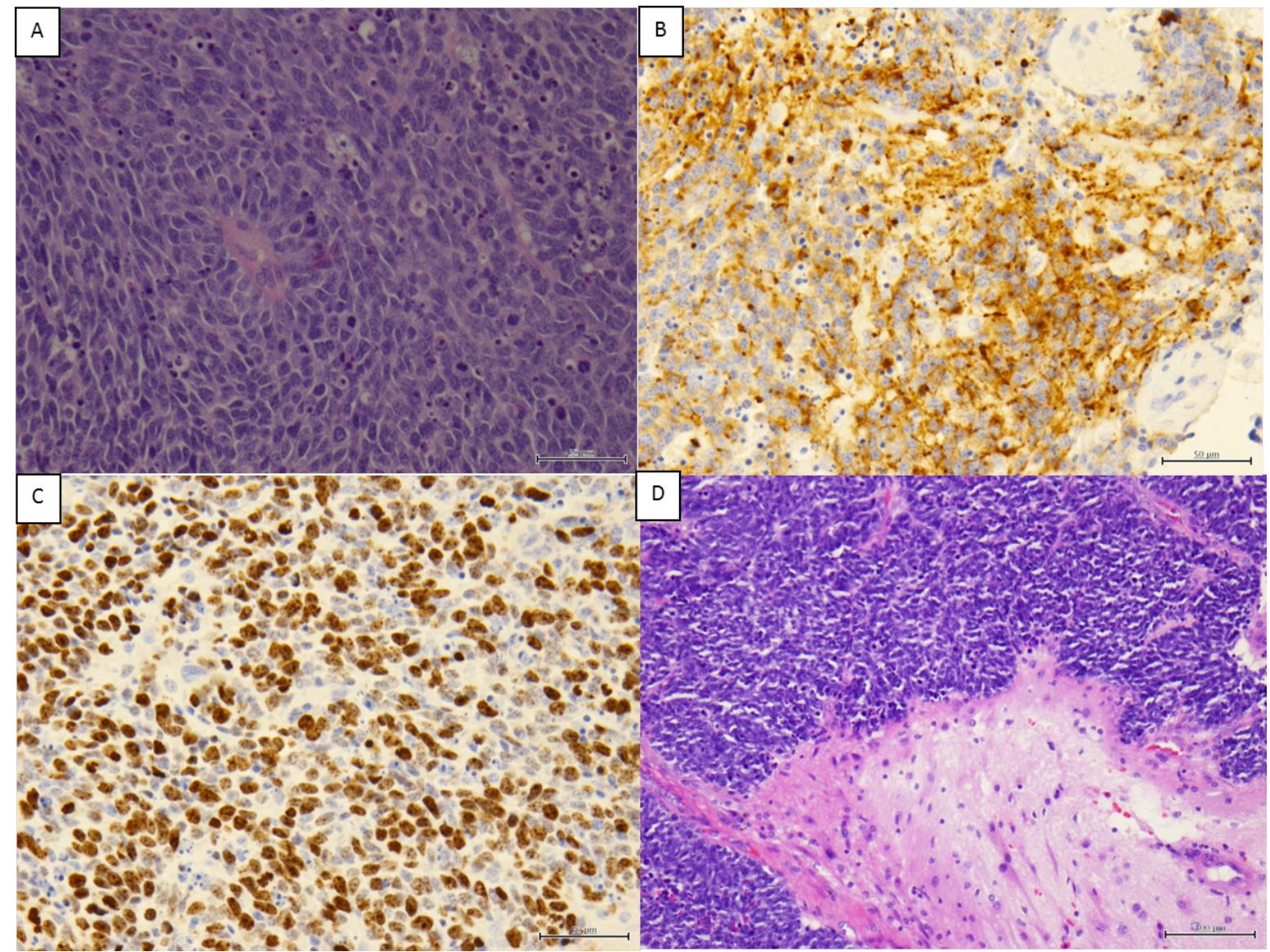

Figure 2: (A) Haematoxylin and eosin (H\&E) stain showing highly cellular tumour with frequent apoptotic cells and scattered mitotic figures. (B)Immunohistochemical stain for synaptophysin, showing cytoplasmic staining of tumour cells, confirming neuroendocrine nature of tumour. (C) Immunohistochemical stain for Ki-67 showing high proliferation index. (D) Olfactory neuroblastoma infiltrating cerebral tissue, H\&E stain, cerebral tissue at lower right.

The patient was offered both post-operative radiotherapy and chemotherapy as he was felt to be high risk from the presence of several poor prognostic factors (higher stage, high grade and positive margin). It was considered feasible to deliver 48 Gy to the areas of risk, with the dose being constrained by his previous 20 Gy of radiation to the retro-orbital area for management of Graves' ophthalmopathy in 1992. As a result of the reduced dose of radiotherapy, this was followed by six cycles of chemotherapy consisting of cisplatin $100 \mathrm{mg} / \mathrm{m}^{2}$ in three divided doses and etoposide $240 \mathrm{mg} / \mathrm{m}^{2}$ in two divided doses. He tolerated chemotherapy well with some minor delays due to neutropenia. The patient has been followed up for 12 years now with regular clinical and MRI surveillance. He remains in remission with no evidence of tumour recurrence. The only long term toxicities reported were left sided cataract and a blocked left lacrimal duct. He has not developed optic nerve or chiasmal damage.

\section{Discussion}

We described an interesting case of a man who presented with an olfactory neuroblastoma that was diagnosed within the irradiation field 8 years after the original radiotherapy for the management of Grave's ophthalmopathy. The tumour could reasonably be ascribed to the prior radiotherapy given that it fits the accepted criteria for radiation-induced tumours, namely that the second tumour (olfactory neuroblastoma) is histologically distinct from the condition that radiotherapy was initially given for (Grave's disease), the tumour was within the prior radiation field and it developed more than 5 years after the radiotherapy [21]. After multi-disciplinary assessment, it was decided to proceed with trimodality treatment (maximal surgical resection, with postoperative chemo-radiotherapy). Despite his previous radiotherapy, post-operative radiotherapy dose was well tolerated and the only late radiation toxicity described was cataracts, which manifested three years after re-irradiation, and anosmia. Chemotherapy was also adequately tolerated. The patient continues on surveillance as late recurrent are possible even up to 15 years from the time of diagnosis [17]. 
There have been only four other case reports of radiation induced olfactory neuroblastoma in the literature [22-25]. Two cases occurred after prior radiotherapy and chemotherapy and outcomes were poor. Kounami et al. reported in 2001 a 17 year old woman diagnosed with olfactory neuroblastoma nine years after the successful treatment of childhood acute leukaemia including 24 Gy prophylactic cranial irradiation, 12 Gy total body irradiation and autologous bone marrow transplantation. Her olfactory neuroblastoma responded briefly to treatment with chemotherapy but she died 11 month later of recurrent disease [24]. McVey et al. reported in 2009 a 61 year old woman who developed metastatic olfactory neuroblastoma 25 years after receiving 60 Gy radiotherapy to the left facial and neck area and MBACOD chemotherapy (methotrexate with leucovorin, bleomycin, doxorubicin, cyclophosphamide, vincristine, and dexamethasone) for the treatment of diffuse large cell poorly differentiated lymphocytic lymphoma. The patient was treated with a palliative course of carboplatin-etoposide but did not respond to treatment [22]. The remaining two cases occurred after prior radiotherapy alone. Perez et al. reported in 2011 a 52 year old female who developed Kadish stage C olfactory neuroblastoma 9 years after 58 Gy whole brain radiotherapy with frontal boost for grade two astrocytoma. The patient was treated with combination of $50 \mathrm{~Gy}$ radiotherapy and chemotherapy consistent of docetaxel, cisplatin, and fluorouracil. However, she relapsed in one year and she died shortly after [23]. Lastly, Park et al. reported in 2008 a 59-year-old woman who was diagnosed 20 years after receiving 54 Gy of post-operative radiotherapy for a pituitary adenoma. She was treated with ifosfamide, cisplatin, and etoposide and remained disease free after 4 years of follow up [25].

\section{Conclusion}

We describe a case of likely radiation-induced olfactory neuroblastoma, adding to the increasingly strong case that prior radiotherapy is a risk factor for these rare tumours. Within the limits of the sparse and heterogeneous literature on these patients, outcomes appear variable but generally worse than reported in the literature for non-radiotherapy related disease. With careful patient selection and treatment, aggressive treatment for such radiotherapy-related cases is feasible and is reasonable option given the limited evidence available.

\section{References}

1. Kumar A, Sethi B, Kumar Y, Mishra JP (2013) Esthesioneuroblastoma arising from the middle meatus. J Cancer Res Ther 9: 99-101.

2. Allen MW, Schwartz DL, Rana V, Adapala P, Morrison WH, et al. (2008) Long-term radiotherapy outcomes for nasal cavity and septal cancers. Int J Radiat Oncol Biol Phys 71: 401-6.

3. Rosenthal DI, Barker JL Jr, El-Naggar AK, Glisson BS, Kies MS, et al. (2004) Sinonasal malignancies with neuroendocrine differentiation: patterns of failure according to histologic phenotype. Cancer 101: 2567-73.

4. Ferlito A, Rinaldo A, Rhys-Evans PH (2003) Contemporary clinical commentary: esthesioneuroblastoma: an update on management of the neck. Laryngoscope 113: $1935-8$.

5. Skarsgard DP, Groome PA, Mackillop WJ, Zhou S, Rothwell D, et al. (2000) Cancers of the upper aerodigestive tract in Ontario, Canada, and the United States. Cancer 88: 1728-38.

6. O'Connor TA, McLean P, Juillard GJ, Parker RG (1989) Olfactory neuroblastoma. Cancer 63: 2426-8.

7. Broich G, Pagliari A, Ottaviani F(1997) Esthesioneuroblastoma: a general review of the cases published since the discovery of the tumour in 1924 . Anticancer Res 17: 2683-706.

8. Leon Barnes, John W. Eveson, Peter Reichart, David Sidransky (2005) Neuroectodermal tumours. In: Pathology and genetics of head and neck tumours. IARC Press, Lyon, France.

9. Jethanamest D, Morris LG, Sikora AG, Kutler DI (2007) Esthesioneuroblastoma: a population-based analysis of survival and prognostic factors. Arch Otolaryngol Head Neck Surg 133: 276-80

10. Kadish S, Goodman M, Wang CC (1976) Olfactory neuroblastoma. A clinical analysis of 17 cases. Cancer 37: 1571-6.

11. Morita A, Ebersold MJ, Olsen KD, Foote RL, Lewis JE, et al. (1993) Esthesioneuroblastoma: prognosis and management. Neurosurgery 32: 706-15.

12. Simon JH, Zhen W, McCulloch TM, Hoffman HT, Paulino AC, et al. (2001) Esthesioneuroblastoma: the University of Iowa experience 1978-1998. Laryngoscope 111: 488-93.

13. Dulguerov P, Allal AS, Calcaterra TC (2001) Esthesioneuroblastoma: a meta-analysis and review. Lancet Oncol 2: 683-90.

14. Nichols AC, Chan AW, Curry WT, Barker FG, Deschler DG (2008) Esthesioneuroblastoma: the massachusetts eye and ear infirmary and massachusetts general hospital experience with craniofacial resection, proton beam radiation, and chemotherapy. Skull Base 18: 327-37.

15. Diaz EM Jr, Johnigan RH 3rd, Pero C, El-Naggar AK, Roberts DB, et al. (2005) Olfactory neuroblastoma: the 22-year experience at one comprehensive cancer center. Head Neck 27: 138-49.

16.Ward PD, Heth JA, Thompson BG, Marentette LJ (2009) Esthesioneuroblastoma: Results and Outcomes of a Single Institution's Experience. Skull Base 19: 13340.

17. Bachar G, Goldstein DP, Shah M, Tandon A, Ringash J, et al. (2008) Esthesioneuroblastoma: The Princess Margaret Hospital experience. Head Neck $30: 1607-14$. 18. Fitzek MM, Thornton AF, Varvares M, Ancukiewicz M, Mcintyre J, et al. (2002) Neuroendocrine tumors of the sinonasal tract. Results of a prospective study incorporating chemotherapy, surgery, and combined proton-photon radiotherapy. Cancer 94: 2623-34.

19. Eich HT, Hero B, Staar S, Micke O, Seegenschmiedt H, et al. (2003) Multimodality therapy including radiotherapy and chemotherapy improves event-free survival in stage C esthesioneuroblastoma. Strahlenther Onkol 179: 233-40.

20. Loy AH, Reibel JF, Read PW, Thomas CY, Newman SA (2006) Esthesioneuroblastoma: continued follow-up of a single institution's experience. Arch Otolaryngol Head Neck Surg 132: 134-8.

21. Murray EM, Werner D, Greeff EA, Taylor DA (1999) Postradiation sarcomas: 20 cases and a literature review. Int J Radiat Oncol Biol Phys 45: 951-61. 
22. McVey GP, Power DG, Aherne NJ, Gibbons D, Carney DN (2009) Post irradiation olfactory neuroblastoma (esthesioneuroblastoma): a case report and up to date review. Acta Oncol 48: 937-40

23. Perez Garcia V, Martinez Izquierdo Mde L (2011) Radiation-induced olfactory neuroblastoma: a new etiology is possible. Oral Maxillofac Surg 15: 71-7.

24. Kounami S, Douno S, Matsubara H, Takayama J, Ohira M (2001) Olfactory neuroblastoma as a second malignant neoplasm in a patient previously treated for childhood acute leukemia. Pediatr Hematol Oncol 18: 459-63.

25. Park KJ, Kang SH, Lee HG, Chung YG (2008) Olfactory neuroblastoma following treatment for pituitary adenoma. J Neurooncol 90: $237-41$.

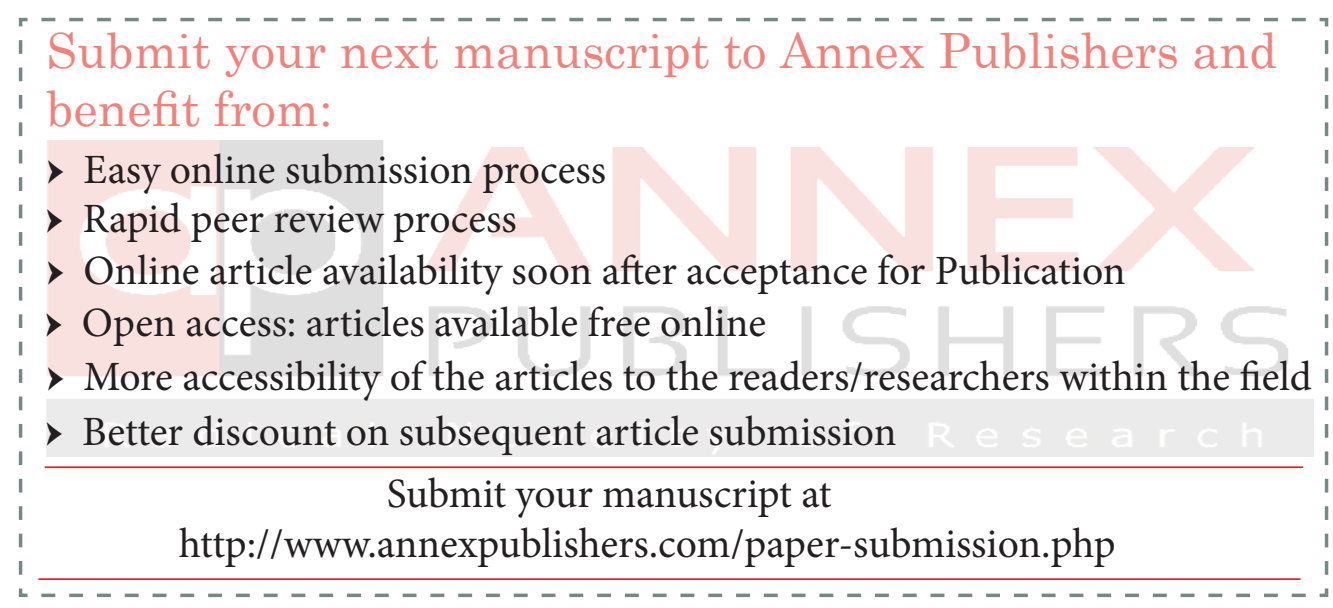

